\title{
ERCP in patient with Roux-en-Y gastric bypass and high grade duodenal stricture across dual lumen-apposing metal stents
}

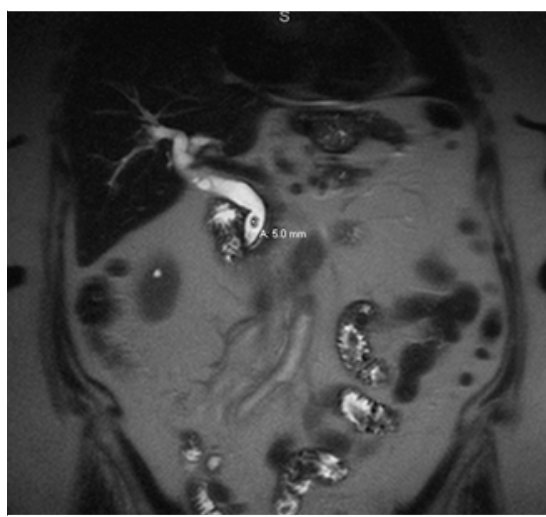

- Fig. 1 Magnetic resonance cholangiopancreatography (MRCP) revealed choledocholithiasis with biliary dilatation.

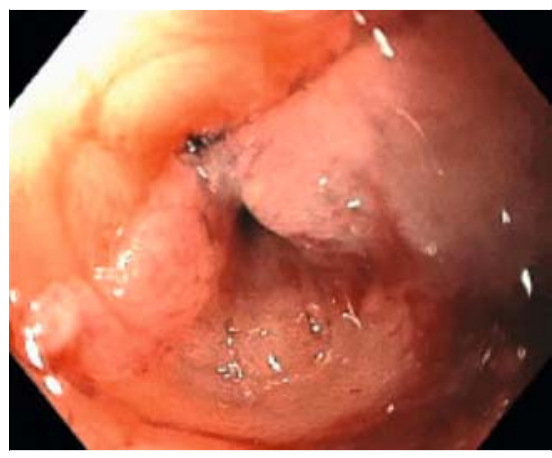

- Fig. 2 High grade duodenal stricture likely due to post-surgical scarring or peptic stricture.

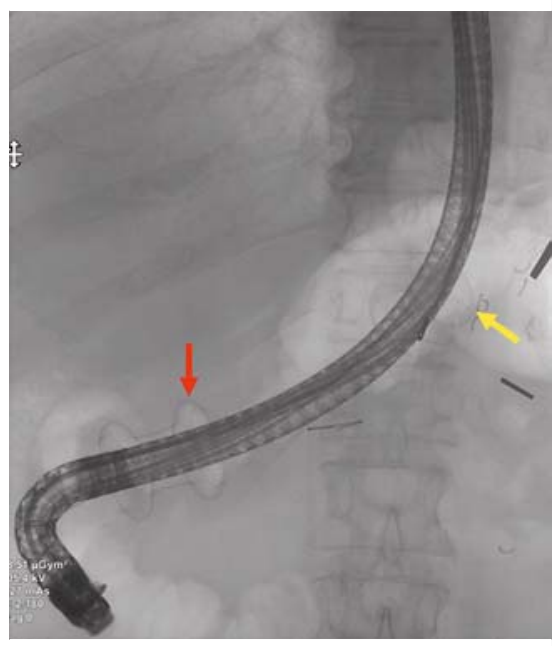

- Fig. 3 Duodenoscope was advanced across dual lumen-apposing metal stents.

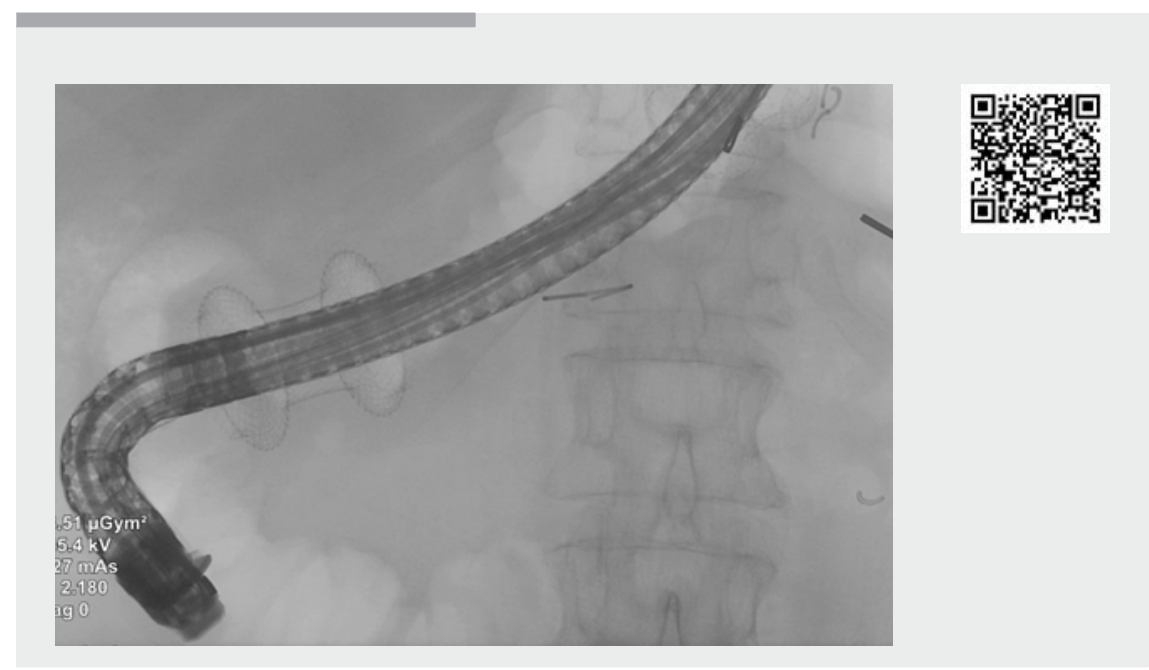

Video 1 Endoscopic ultrasound-guided placement of gastrogastric lumen-apposing metal stent (LAMS) and subsequent placement of a duodenal LAMS to enable endoscopic retrograde cholangiopancreatography in a patient with gastric bypass.

Endoscopic ultrasound-guided lumenapposing metal stents (LAMS) placement is a minimally invasive modality that has been increasingly utilized in patients with challenging gastrointestinal anatomy [1].

An 82-year-old woman with a history of Roux-en-Y gastric bypass (RYGB), multiple abdominal surgeries, and choledocholithiasis, which had been treated with laparoscopy-assisted endoscopic retrograde cholangiopancreatography (ERCP), complicated by duodenal perforation, and repaired by open surgery, was admitted for right upper quadrant abdominal pain. Magnetic resonance cholangiopancreatography (MRCP) revealed choledocholithiasis with biliary dilatation ( Fig.1). Given the high likelihood of extensive adhesions from prior abdominal surgery, laparoscopy-assisted ERCP posed a higher risk of complication. After discussion of various options for accessing the biliary system, an endoscopic ultrasound (EUS)-directed transgastric ERCP was pursued. First, a LAMS was deployed to obtain access to the gastric remnant under endosonographic and fluoroscopic guidance. The patient returned in 3 weeks after the tract was mature for ERCP. However, a high-grade duodenal stricture (>Fig.2), which is likely due to post-surgical scarring or peptic stricture, was unexpectedly found before reaching the biliary system. The stricture was treated with $20 \mathrm{~mm} \times 10 \mathrm{~mm}$ LAMS placement under endosonographic and fluoroscopic guidance. She returned in 2 weeks for subsequent ERCP through dual transluminal connection consisting of gastrogastrostomy and duodenal LAMS. The duodenoscope was advanced through gastrogastrostomy and duodenal LAMS to the major papilla without difficulty ( $\mathbf{F i g . 3}$ ). Biliary sphincterotomy and plastic biliary stent placement were performed. A large amount of sludge and stone was extracted. She was discharged the same day with improvement in symptoms. All stents were removed 6 weeks after the ERCP without complications.

With advanced application of LAMS, we described a novel case of an EUS-directed 
transgastric ERCP procedure in a patient with RYGB anatomy in conjunction with a benign enteric stricture, which was performed through a dual transluminal conduit comprised of gastrogastrostomy and duodenal LAMS (-Video 1). This highly effective approach should be considered in clinical circumstances where balloon enteroscopy-assisted ERCP is technically challenging and when laparoscopy-assisted ERCP is not feasible [2, 3].

\section{Endoscopy_UCTN_Code_TTT_1AR_2AK}

\section{Competing interests}

The authors declare that they have no conflict of interest.

The authors

\section{Kornpong Vantanasiri ${ }^{1}$, Guru Trikudanathan ${ }^{2}$}

1 Department of Medicine, University of Minnesota, Minnesota, USA

2 Department of Medicine, Division of Gastroenterology, Hepatology and Nutrition, University of Minnesota, Minnesota, USA

\section{Corresponding author}

\section{Guru Trikudanathan, MD}

Division of Gastroenterology, Hepatology and Nutrition, 420 Delaware Street SE, MMC 36, Minneapolis, Minnesota, USA 55455

Fax: +1-612-626-3107

triku001@umn.edu

\section{References}

[1] Jain D, Chhoda A, Sharma A et al. De-novo gastrointestinal anastomosis with lumen apposing metal stent. Clin Endosc 2018; 51 : 439-449

[2] Dhindsa BS, Dhaliwal A, Mohan BP et al. EDGE in Roux-en-Y gastric bypass: How does it compare to laparoscopy-assisted and balIoon enteroscopy ERCP: a systematic review and meta-analysis. Endosc Int Open 2020; 8: 163-171

[3] Bukhari M, Kowalski T, Nieto J et al. An international, multicenter, comparative tria of EUS-guided gastrogastrostomy-assisted ERCP versus enteroscopy-assisted ERCP in patients with Roux-en-Y gastric bypass anatomy. Gastrointest Endosc 2018; 88 : 486-494
Bibliography

Endoscopy 2021; 53: E189-E190

DOI 10.1055/a-1234-6012

ISSN 0013-726X

published online 2.9.2020

(c) 2020. Thieme. All rights reserved.

Georg Thieme Verlag KG, Rüdigerstraße 14, 70469 Stuttgart, Germany

\section{ENDOSCOPY E-VIDEOS \\ https://eref.thieme.de/e-videos}

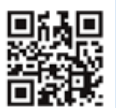
Endoscopy E-Videos is a free access online section, reporting on interesting cases and new techniques in gastroenterological endoscopy. All papers include a high quality video and all contributions are freely accessible online.

This section has its own submission website at https://mc.manuscriptcentral.com/e-videos 